\title{
Momentum, December 2004
}

Population Council

Follow this and additional works at: https://knowledgecommons.popcouncil.org/ series_newsletters_momentum How does access to this work benefit you? Let us know!

\section{Recommended Citation}

"Momentum, December 2004," newsletter. New York: Population Council. 


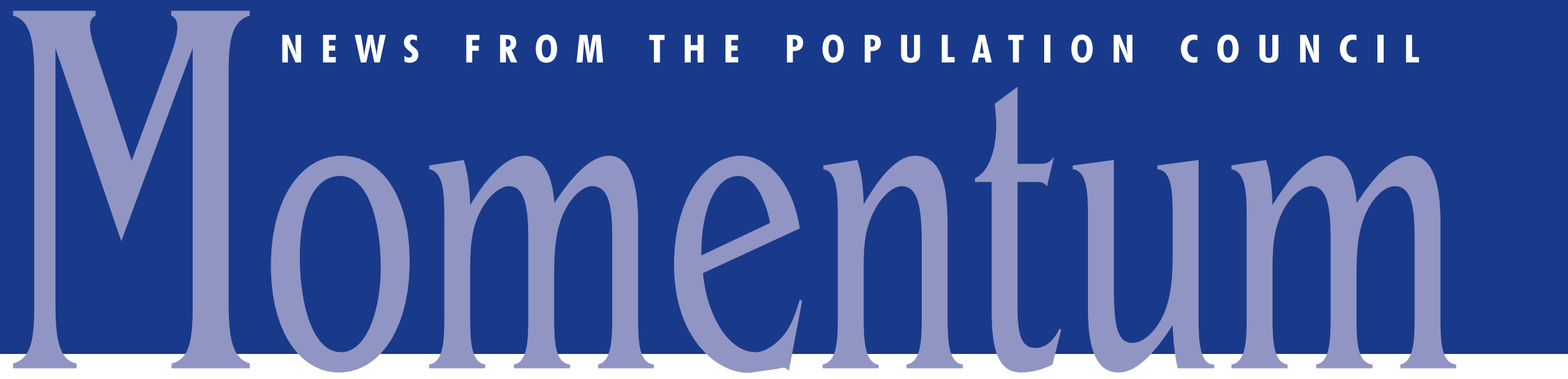

DEC E M B E R 20004

\section{Protecting girls' rights}

Child marriage is one of the largest, most neglected human rights abuses in the developing world today. Over the next decade, if present marriage patterns continue, more than 100 million girls will be married before they reach 18- "children" as defined by the United Nations Convention on the Rights of the Child. Marriage below the age of 18 is widely practiced, and, in some settings, a substantial proportion of girls will marry at 15 or younger, often to older men.

Significantly elevated health risks and poverty frequently are the norm for the youngest, first-time mothers and their children. Married girls face other risks, with marriage bringing an abrupt, unprepared, and unprotected initiation into sexual relations. In the context of the growing HIV epidemic, child marriage may expose girls, under pressure to become pregnant, to HIV infection or other sexually transmitted infections (STIs). In many countries, the low age of marriage and associated childbearing also drives population growth, shortening the years between generations.

Through its new project, "Protecting Girls' Rights Across the Marital Boundary," the Population Council is addressing child marriage from health, human rights, and social development perspectives. The project builds on the Council's eight years of research on policies and interventions to ease the transition to adulthood for young people in more than a dozen countries in Africa, Asia, the Middle East, and Latin America.

The Council is working in partnership with U.N. agencies, government ministries, international and local organizations, and other research groups to provide evidence to support the end of child marriage, create schooling options and safe spaces for adolescent girls, and develop appropriate HIV-protection strategies for married girls.

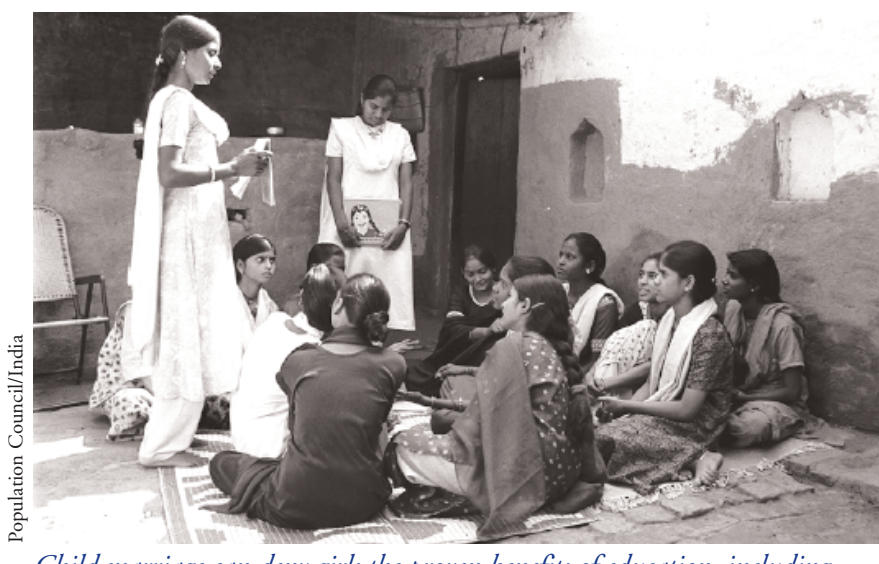

Child marriage can deny girls the proven benefits of education, including improved health, lower fertility, and increased economic productivity.

As Judith Bruce, director of the Council's Gender, Family, and Development program, has emphasized, "We can't address the world's demographic and health challenges without upholding the rights and improving the opportunities for coming-of-age girls in the poorest countries."

\section{A challenge met}

Generous support from Population Council trustees, alumni, staff, and friends helped the Policy Research Division (PRD) meet a one million dollar endowment challenge grant from The Andrew W. Mellon Foundation-a year before the deadline. Special thanks go to The Fred H. Bixby, The William and Flora Hewlett, The John D. and Catherine T. MacArthur, and the Adolph and Ruth Schnurmacher foundations for their generous grants and to the Mellon Foundation for matching each endowment gift.

Now totaling more than $\$ 2$ million and still growing, the endowment will provide an ongoing revenue stream to sustain research on such concerns as the unmet need for contraception, poverty in the rapidly expanding urban centers of developing countries, diffusion dynamics, and population aging; and to launch new projects on emerging trends.

\section{Council microbicide enters efficacy trial}

In March 2004, the Population Council launched a large-scale, three-year clinical trial of its lead candidate microbicide, Carraguard $^{\circledR}$, to test its efficacy in blocking the HIV virus and determine its safety over an extended period. If proven effective, this colorless, odorless gel will offer a powerful new tool against AIDS. Globally, women's rates of HIV infection outpace men's, and the existing strategies for prevention—abstinence, condom use, and mutual monogamy between HIV-negative partners - are not practical for most women. A successful trial will also demonstrate "proof of concept"-that consistent use of microbicides is a feasible means of thwarting HIV infection. With 60 microbicide candidates under development worldwide, proof of concept would be a significant achievement. Because of the urgent need for a female-controlled product useful to all women, the Council has focused to date on a vaginal, noncontraceptive microbicide; among additional microbicide formulations the Council has under development is a contraceptive formulation.

The Carraguard trial is being conducted at three sites in South Africa in collaboration with the Medical University of Southern Africa, the University of Cape Town, and the Medical Research Council. A massive recruitment effort is under way to identify more than 6,000 HIVnegative, nonpregnant volunteers who can commit two years to the study.

continued on page 4

\section{The feminization of the pandemic}

- In Africa today, young women aged 15-24 are two and a half times more likely than young men to be infected.

- In sub-Saharan Africa, nearly 60 percent of all adults living with HIVIAIDS are female.

- In South Africa, of the first I,500 women screened for the Carraguard trial, more than 20 percent were ineligible because of their HIV-positive status. 


\section{U.S. government recognition for excellence in research}

Policy Research Division senior associate James F. Phillips received the 2004 Marjorie Horn Operations Research Award* presented by the United States Agency for International Development (USAID) during a ceremony in Washington, DC, on August 3rd.

Phillips was honored for his pioneering approaches to program-relevant research, his dedication to the improvement of primary and reproductive health programs, his support for building the capacity of researchers and institutions in developing countries, and his perseverance in working to bridge the gap between research and program implementation.

During his 35-year career, Phillips has been instrumental in the development of demographic surveillance systems and in designing, implementing, and scaling up programs and field experiments in primary health care. His leadership was pivotal to the establishment of two model research projects in the developing world: the Matlab Project of the International Centre for Diarrhoeal Disease Research in Bangladesh and the Navrongo Health Research Centre in Ghana.

In 2000, Phillips and his colleagues helped build consensus for health care reforms at the national, regional, and community levels, leading to the launch of the Community-based Health Planning and Services (CHPS) project of the Ghana Health Service/Ministry of Health. CHPS is continuing to mobilize volunteers, resources, and cultural institutions to support community-based primary health care throughout Ghana and is serving as a model for other countries in sub-Saharan Africa.

Phillips has worked for the Population Council in Bangladesh, the Philippines, Thailand, and the United States. He holds a Master of Science degree in population studies from the University of Hawaii and a doctorate in sociology from the University of Michigan.

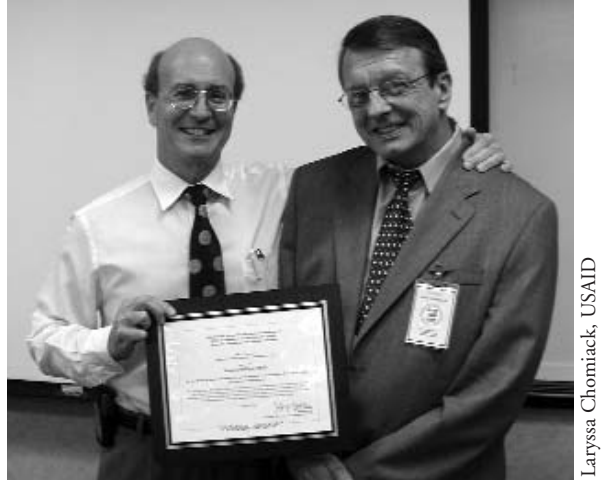

Jim Phillips accepts the award from USAID's Jeff Spieler.

*The Marjorie Horn Operations Research Award is named for USAID's former Deputy Chief of the Research, Technology, and Utilization Division, who held the post prior to her untimely death in September 2002. Her commitment to the conduct and utilization of program research for the betterment of the lives of women and men around the world was inspirational to all who worked with her.

\section{Year-end gifts}

Unrestricted gifts to the Population Council's Annual Fund provide core support for the Council's research and evidence-based advocacy, and its population, health, and development policies and programs.

We thank the many individuals and foundations that already have made a gift to the 2004 Annual Fund. There is still time to contribute or make an additional gift prior to December 31, 2004. Cash gifts can be made by check or credit card as well as online at www.popcouncil.org/supporting/ secureorder.html.

The Council also welcomes gifts of appreciated securities, bequests, charitable remainder and lead trusts, and designations of the Council as beneficiary of insurance policies or pension plans. For further information contact Ruth Kalla Ungerer, Director of Development, Population Council, One Dag Hammarskjold Plaza, New York, NY 10017, (212) 339-0515, or rungerer@popcouncil.org.

\section{Perspectives on sexuality in India}

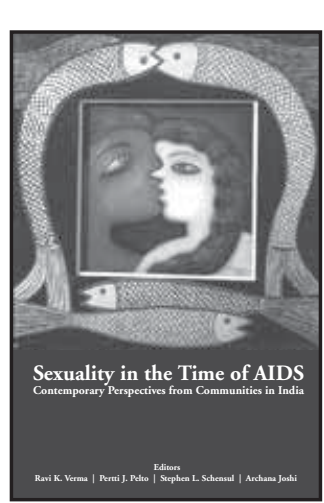

As recently as the last decade, there was surprisingly little solid research on sexuality in India. Yet the availability of accurate information about contemporary sexual behaviors and attitudes is essential to the design of interventions to reduce risky behaviors and prevent the sexual transmission of HIV/AIDS.

Sexuality in the Time of AIDS: Contemporary Perspectives from Communities in India (2004, SAGE Publications) draws upon ten years of research related to the cultural and social factors in Indian society that contribute to the risk of HIV infection. The four co-authors/coeditors of the book-among them Population Council program associate Ravi Verma-have compiled the research findings of more than two dozen social scientists on a range of salient issues. Aimed at public health professionals, policymakers, educators, activists, and managers of nongovernmental organizations, the book presents case studies from disparate segments of the nation's 1.1 billion people, rural and urban, ranging from "Street Boys and Male Sex Workers in Bangalore" to "Married
Women in Extramarital Relationships in a Rural Area of Gujarat.'

The Secretary of the Indian Government's Department of Health, J.V.R. Prasada Rao, comments in the introduction, "The openness advocated in these essays needs to be adopted by both the government and civil society. . . . I feel extremely happy and satisfied to see such a large volume of material brought together. ..."

Each chapter provides a unique perspective, advancing the authors' goal of broadening discourse on sexuality in India. Researchers and others working to stem the spread of HIV/ AIDS may find the final three chapters to be of particular interest. Grouped as "Lessons Learned," they discuss different sexual behaviors, multimethod approaches to research on sexuality, and guidelines for policymaking and interventions in the time of AIDS.

Ravi Verma studies male sexuality and sexual health and their relationship to HIV/AIDS risk and domestic violence. Working from the Council's New Delhi office, he also conducts research to assess the impact of HIV/AIDS on families and children.

"India is teetering on the edge of the AIDS abyss," he says, "but it is not too late to pull back if the right steps are taken quickly. Frank and open discussion of sexual behavior is absolutely vital, and we hope that our book can serve as a catalyst in that process." 


\section{Dissemination: Making results known}

The Population Council disseminates its findings widely to ensure that its research makes a positive difference in people's lives. Dissemination takes many forms: meetings with policymakers and program managers around the world; presentations and distribution of findings at major public health, social science, and biomedical conferences; media briefings and interviews; publication of books, working papers, and two internationally recognized, peer-reviewed journals, Population and Development Review and Studies in Family Planning; and regular updates and information about programs, projects, and activities on its Web site.

In the last 12 months, Council staff members have made presentations in Asia, Africa, North and South America, and Europe, including:

- In July Council research was presented at 55 sessions during the XV International AIDS Conference in Bangkok, Thailand. At the American Public Health Association's four-day annual meeting in Washington, DC, in November, 49 Council research studies were discussed at roundtable, panel, and poster sessions. Information about Council research was distributed at both conferences, which drew a combined total of approximately 28,000 delegates from 160 countries.

- A booklet and video developed for the Carraguard trial (see related article) are both available on the Council's Web site, as is a presentation co-authored by Council researcher Barbara Friedland on the video production process. These materials also were presented in March at Microbicides 2004 in London and at the Bangkok AIDS Conference.

- Council immunologist Melissa Pope presented "Dendritic cells and HIV infection" in July at the 5th International Workshop on Oral Health and HIV Disease in AIDS, in Phuket, Thailand, sponsored by the National Institute of Dental and Craniofacial Research of the NIH.

- In August, at the annual meeting of the Society for the Study of Reproduction, andrologist Matthew Hardy discussed "Stress, Behavior, and Reproduction: Neuroendocrine Control of Gonadal Function" at the University of British Columbia/Vancouver.

- Population Council staff members gave eight presentations at the Global Health Council's annual conference in Washington in June, with Judith Bruce, program director of the Council's Gender, Family, and Development Program, addressing a special forum on "Early Marriage:Advancing the Global Agenda.” In late November, Bruce participated in a panel moderated by New York Times columnist Nicholas Kristof on the global status of girls, hosted by the Council on Foreign Relations.

Past presentations as well as upcoming events are highlighted at www.popcouncil.org/presentations.

With as many as 50,000 visitors a month, the Population Council's Web site serves as a key forum for disseminating research findings. Currently being upgraded, the redesigned site offers a more intuitive navigation system and more material available in Spanish and French, with pages being added in Arabic.

\section{Protecting girls' rights}

continued from front cover

The Council's focus on supporting girls in their transitions to adulthood takes many forms:

- Increasing access to school and improving schooling experiences;

- Defining appropriate health and service paradigms for unmarried adolescent girls;

- Expanding safe, appropriate livelihood opportunities for older adolescent girls;

- Expanding health services, social supports, and opportunities for married adolescents; and

- Encouraging girls to participate in public activities that build leadership and decisionmaking skills, physical strength, and social mobility.

For example:

\section{Expanding options in Ethiopia for unmarried girls}

In collaboration with Ethiopia's Ministry of Youth, Sports, and Culture, the Population Council completed two surveys of adolescents aged 10 to 19 in the capital city of Addis Ababa and in Amhara, a rural region with extremely high rates of child marriage (50 percent of girls wed by age 15; 80 percent by age 18). Eighteen percent of the girls interviewed in Addis Ababa migrated to the city in response to threats of child marriage. These girls often ended up alone, in dire poverty, engaging in low-paid, often dangerous work; and, despite the presence of many youth-serving programs, only seven percent of the girls surveyed had been reached. The Council has continued working with the ministry to design two interventions targeting vulnerable adolescents: one in Addis Ababa to promote girls' safety and social networks, the other in the Amhara region to upgrade schools and encourage girls to stay in school and engage parental support for delayed marriage through livelihood activities.

\section{First-time parents in India}

Situated in two rural sites in India, the First-time Parents Project is testing ways to help young wives who are newly married, first-time pregnant, and/or postpartum increase their knowledge of reproductive health and their ability to act in their own interests.

During the period surrounding marriage and first birth, the girl, her husband, and her extended family may be most open to change. To reach these socially isolated girls, the Council, in collaboration with the Child In Need Institute and Deepak Charitable Trust, developed an approach that includes in-home visits, family discussions, and the creation of over 60 community-based women's educational and social groups.

These and other projects are contributing knowledge about—and drawing attention tothe practice of child marriage. More information, including specific briefing sheets on child marriage in Ethiopia, Mali, Mozambique, Nigeria, and Zambia, is available at www.popcouncil.org/talmar.html.

\section{Vietnam fellows}

\section{continued from back cover}

and discussing common research interests, and opportunities to participate in research projects. The network is especially valued by researchers in the provinces, for whom isolation can be a real problem. A modest research grant program makes it possible for fellows to develop and implement research initiatives specific to their country and province. Every year, a national research meeting brings fellows together to discuss research findings, and travel grants promote their participation in international meetings.

In outlining his hopes for the program, Robert Miller, the Council's fellowship program director, notes, “The fellows' research on previously 'taboo topics' in Vietnam is expected to be disseminated widely, both in scientific and popular publications, to spur broad discussion of the findings, to stimulate additional research, and, ultimately, to contribute to changes in societal norms and behavior.'

Gauging progress in increasing Vietnam's strength in the health and social sciences and helping to launch new fields of research in reproductive health and sexuality will take time. "However," says Jane Hughes, the Council's representative in Hanoi, "we are proud of the program's strong record, and we are confident that its graduates will be central contributors to achievement of these objectives in coming years." 


\section{FRONTIERS: Using evidence to improve service delivery}

Reproductive health service providers face more challenges than ever: the HIV/AIDS pandemic, increasing rates of other sexually transmitted infections, persistently high rates of maternal mortality in resourcepoor settings, and a large population of new clients, including adolescents and men. Since 1998, the Population Council's Frontiers in Reproductive Health Program (FRONTIERS), funded by the United States Agency for International Development (USAID), has employed "operations research" to identify the most effective and affordable ways to address critical reproductive health issues.

Findings from this practical research methodology are enabling governments and program managers around the world to advance and support voluntary programs to reduce unintended pregnancy and promote healthy behaviors. Strong working relationships with health agencies, community- and faith-based groups, and policymakers in 30 countries are increasing understanding of how to improve coverage, quality, and sustainability of services, and of the areas in service delivery over which program managers can actually have influence.

FRONTIERS works in the following areas:

- Intervention and evaluation studies to demonstrate the feasibility and acceptability of new service-delivery approaches or to test the impact and cost-effectiveness of different policy options

- Technical assistance in the scaling-up or adaptation of successful interventions to different locales

- Building local operations research capacity in collaboration with donor agencies and developingcountry service providers

The research cycle does not end when data have been analyzed. FRONTIERS communicates results globally, promoting best practices and facilitating the application of results by policymakers and program managers. Findings are disseminated through FRONTIERS publications, journals, international conferences, meetings, and stakeholder workshops, and on the Internet at www.popcouncil.org/frontiers.

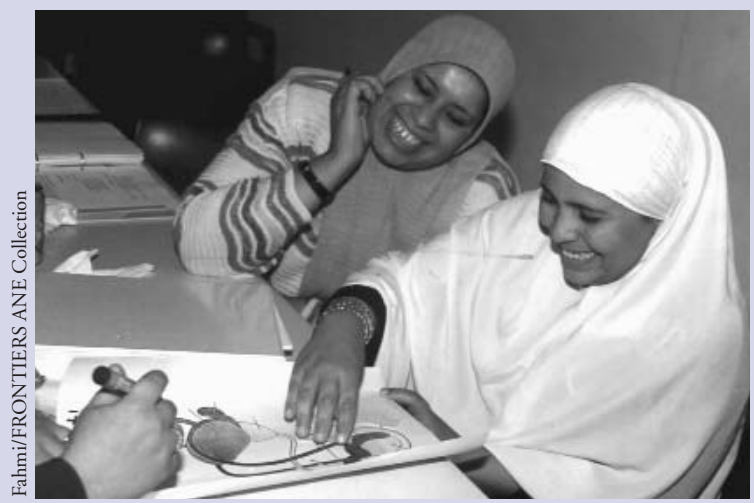

A FRONTIERS study in Egypt found that clients welcomed discussion of sexuality during family planning counseling but preferred to have the service provider raise the subject.

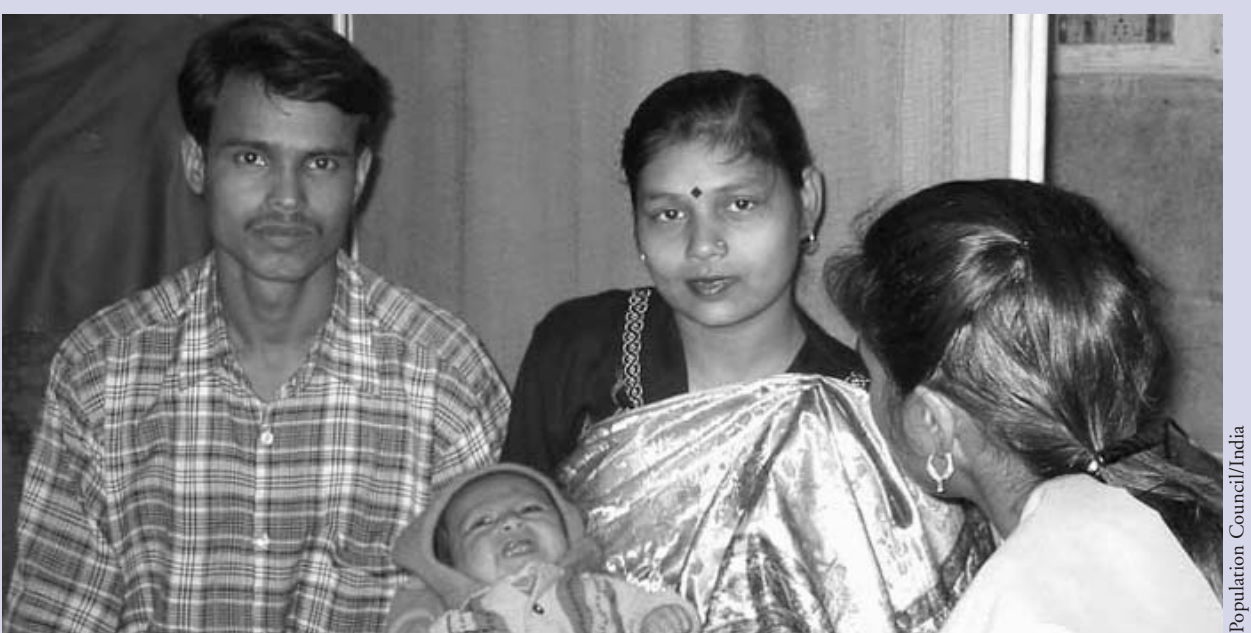

Both men's and women's family planning knowledge and behaviors changed markedly after participating in the "Men in Maternity" program in New Delhi. A similar FRONTIERS study is under way in KwaZulu-Natal, South Africa.

FRONTIERS collaborates with 125 partner organizations in 30 countries in Africa, Asia, the Middle East, and Latin America and the Caribbean. These are three current projects.

\section{Kenya: Adolescent reproductive bealth}

In western Kenya, where rates of HIV/AIDS are high and rising, FRONTIERS, together with the Program for Appropriate Technology in Health (PATH), tested the effectiveness of community, school, and clinic interventions in improving young people's knowledge of reproductive health, delaying the onset of sexual activity, and increasing access to adolescent-friendly reproductive health services. More than 100 teachers, 80 religious leaders, and 850 peer educators were trained for the intervention, which was strongly endorsed by the community. It led to greater discussion and understanding of reproductive health and encouraged safer sexual behavior among young people. FRONTIERS and PATH are providing technical assistance to the Government of Kenya to scale up activities nationally.

\section{India: Men in maternity care}

In India, FRONTIERS and the Employees' State Insurance Corporation (ESIC), a government-affiliated social security system for low-income workers, conducted a study in ESIC health clinics on the effect of men's involvement in their partners' prenatal and postpartum care. According to the study, men had great interest in participating in maternal and child health care, couples' communication improved, and contraceptive use increased significantly. Providers and clients alike expressed satisfaction with the new services. The model was relatively inexpensive to scale up and is being adopted at additional clinics and hospitals in New Delhi. Moreover, the training and counseling model is being considered for use in other Indian states, and program materials are available for use in other countries.

\section{Guatemala: Increasing access to long-term contraceptives}

In Guatemala, FRONTIERS developed and is testing a new service-delivery model to expand access to the long-term contraception offered by intrauterine devices (IUDs) for women living in rural areas. The project includes training (or retraining) for nurses and nurse auxiliaries in IUD counseling, insertion, and removal, and in case management and outreach. The training emphasizes competency and requires the nurses to perform five supervised IUD insertions for clients in order to obtain certification. To date, 45 of 92 trained nurses have received certification; the training is ongoing. The certified nurses averaged seven insertions in the first three months after certification, as compared with two insertions in the previous year.

\section{FRONTIERS} collaboration with Family Health International.

More information is available at www.popcouncil.org/frontiers. 


\section{Antiretrovirals and patient compliance in Thailand}

Vigorous prevention efforts enabled Thailand to avert some five million HIV infections during the 1990s. The number of new infections fell from a high of approximately 140,000 in 1991 to 21,000 in 2003 . Now the Thai government has made a commitment to treating its approximately 700,000 HIV-positive citizens.

Until recently, AIDS patients on antiretroviral (ARV) therapy had to juggle complex regimens involving dozens of pills a day. "Partly as a result," according to Philip Guest, program associate and country representative for the Population Council in Thailand, "the focus of global AIDS efforts has been on prevention and support services. However, with treatment now simplified to as few as two pills daily and access to antiretroviral drugs expanding, widespread treatment is now possible. Treatment is also less expensive and much easier to manage."

Nevertheless, ARVs still require rigorous adherence to a twice-a-day schedule: To be effec-

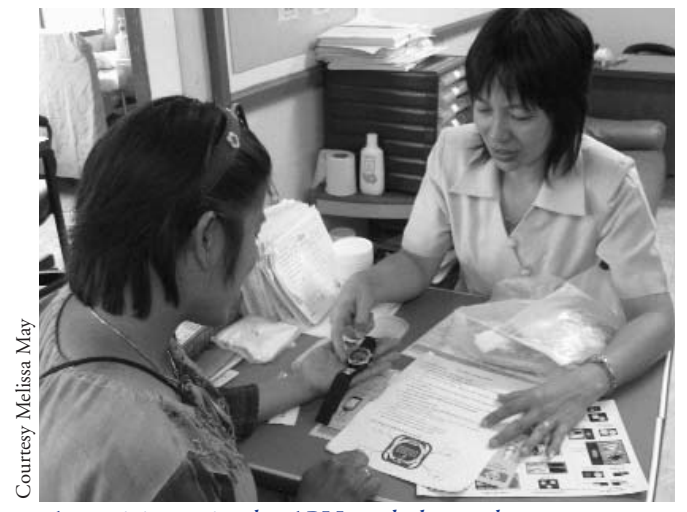

A participant in the ARV study learns how to use a watch with an alarm to remind her to take her medication twice a day. tal and at clients' homes. tive, the pills must be taken 12 hours apart with only an hour's leeway. Even in the United States, where people are accustomed to taking prescription drugs, only about half of the patients with a prescription take the drug as directed. As Thailand continues to invest in treatment-some 15,000 Thais were in treatment by the end of 2003, up from about 2,500 a year earlierpatient compliance will be critically important.

Horizons, the Council's AIDS operations research program, supported by the United States Agency for International Development (USAID), and its local partners completed a large study in 2002 assessing access to care. The Thai government then asked Horizons to work with them to develop and evaluate alternative approaches to the provision of care. Subsequently, two new approaches were developed to compare with the standard of care currently offered to HIV-positive patients by the Ministry of Public Health. The second study arm provides ARV therapy counseling by hospital staff, using the practical guidelines developed by Horizons and its partners. The third arm includes the same counseling, but also involves HIVpositive volunteers who provide peer education, additional counseling, and support at the hospi-

Fifteen hospitals have been assigned to each study arm, for a total of 45 study sites. Findings from this research will be used to help strengthen and scale up the ARV treatment program throughout Thailand, whose leaders hope to have 50,000 people in treatment by the end of 2004 .

\section{Momentum}

Momentum is a semiannual newsletter of the Population Council. Information may be reproduced without permission, provided it is distributed free of charge and the source is acknowledged.
Writer

Editor

Copyeditor

Designers
Suzie Elliott

Ruth Kalla Ungerer

Robert Heidel

Y. Christina Tse

Mike Vosika

\section{Population Council}

One Dag Hammarskjold Plaza

New York, NY 10017

Phone: 212-339-0500

Fax: 212-755-6052

E-mail: pubinfo@popcouncil.org

http://www.popcouncil.org

REGIONAL OFFICES

Latin America and the Caribbean:

Mexico City, Mexico

South and East Asia: New Delhi, India

Sub-Saharan Africa: Accra, Ghana

West Asia and North Africa: Cairo, Egypt

The Population Council is an international, nonprofit, nongovernmental organization that seeks to improve the well-being and reproductive health of current and future generations around the world and to help achieve a humane, equitable, and sustainable balance between people and resources. The Council conducts biomedical, social science, and public health research and helps build capacities in developing countries. Established in 1952, the Council is governed by an international board of trustees. Its New York headquarters supports a global network of 20 regional and country offices.

\section{ISSN 1535-0525}

(C) 2004 The Population Council, Inc. Printed in the USA on recycled paper

\section{Council microbicide}

\section{continued from front cover}

By the end of October 1,500 women were enrolled and randomly and anonymously assigned to one of two study groups. Not even the researchers know which group, to ensure they do not inadvertently cue participants and affect their behavior. One group is using the Carraguard gel, the other a placebo. Each group is instructed to use both a condom-the safest known way to protect against HIV/AIDS—and a gel during intercourse. Measurable infection rates are anticipated in both groups due to noncompliance; both receive benefits including free pap smears, condoms, counseling, and testing for sexually transmitted infections (STIs) and HIV/AIDS. Participants with STIs are treated before beginning the trial, and HIV-positive women are referred to hospital programs.
"When we analyze the final data three years from now,” says Pekka Lähteenmäki, director of the Population Council's Carraguard trial, "we will learn to what extent Carraguard protects women from HIV/AIDS. No one expects 100 percent protection, but even 50 percent efficacy could translate into hundreds of thousands, perhaps millions, of people being spared this disease."

Funding from a dozen major grantmaking institutions - in particular USAID - is supporting the Population Council's search for a viable microbicide. A \$20-million donation from the Bill and Melinda Gates Foundation has contributed significantly to this Carraguard trial. For more information, please visit our Web site at www.popcouncil.org/microbicides.

\section{Developing and sharing research tools}

With funding from the United States Agency for International Development (USAID) and in partnership with the Carraguard study sites, Council researchers have tested and honed tools critical to the trial process, including an informed-consent form, a booklet, and a 25-minute recruitment video. These materials, available in four languages, help to ensure that potential study volunteers understand the trial; facilitate recruitment and retention; and make certain that participants at all three sites get the same information. The August 2004 issue of Sexually Transmitted Diseases published an article by Council scientists who developed an accurate, rapid, and inexpensive method for verifying use of the vaginal applicator, an important tool for assessing and improving compliance. 


\title{
(F Population Council
}

One Dag Hammarskjold Plaza

New York, New York 10017 USA

\section{NEWS FROM THE POPULATION COUNCIL}

\author{
December 2004
}

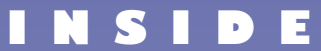

Protecting girls' rights

Council microbicide trial

A challenge met

Dissemination: Making results known

FRONTIERS: Using evidence to improve service delivery

Antiretrovirals in Thailand

Award for excellence in research

\section{Perspectives on sexuality} in India

\section{Year-end gifts}

\section{Stay connected}

We want to be sure all Population Council alumni have the opportunity to stay in touch through Momentum. Contact Rob O'Sullivan, manager, Annual Fund and alumni relations, at 212-339-05II or rosullivan@ popcouncil.org to share your news or comments about Council projects. Thank you.

\section{Vietnam fellows bring research home}

Conservative social norms in Vietnam traditionally have precluded discussion of such public health issues related to sexuality as contraceptive decisionmaking, violence against women, and adolescent behaviors. With the advent of HIV/AIDS, public health training has fast become vital to ensuring accurate dissemination of information about how the disease is spread, who is most vulnerable, and the most promising actions for prevention, care of those infected, and mitigation of the effects on families and the larger community.

Strengthening local capacity is a key component of the Population Council's mission. Working with the Ministry of Health and with support from an anonymous donor, the Council established a public health fellowship program for Vietnamese professionals in 1994. Fellowship training was further expanded in 2002 by a grant from The Ford Foundation establishing the "Fellowship Program for Vietnamese Professionals in Reproductive Health, Sexuality, and Social Sciences," implemented collaboratively with the Hanoi School of Public Health. Together, these two programs have provided training to 100 Vietnamese researchers, with another 21 due to complete their Master's in Public Health by mid-2005. They have pursued high-quality, cross-disciplinary master'slevel training in academic institutions in the United Kingdom, the Netherlands, and Australia, as well as such U.S. universities as Harvard, Columbia, UCLA, Berkeley, and Johns Hopkins. The Vietnam fellows have produced original research on topics ranging from low-birth-weight infants to the vulnerability of fishermen to HIV infection.

In partnership with the Hanoi School of Public Health and the Ho Chi Minh City University of Medicine and Pharmacy, the Council has designed a new initiative to support returned fellows and further strengthen research capacity in Vietnam. The Health Research for Development Initiative offers returned fellows a network for sharing information continued on page 2

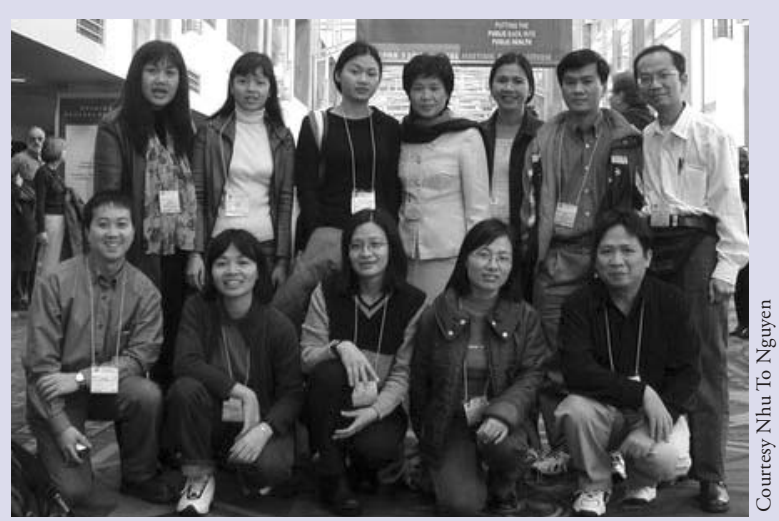

Vietnam public health fellows gathered for a group picture at the 2002 American Public Health Association annual meeting in Philadelphia. 